\title{
Rainfall Trends in the District of Ramallah and Al-Bireh, Palestine
}

\author{
Hussein Al-Rimmawi ${ }^{1}$, Marwan Ghanem ${ }^{1}$, Ibrahim Shalash ${ }^{2}$ \\ ${ }^{1}$ Associate Professor, Geography Department, Birzeit University, Birzeit, Palestine \\ ${ }^{2}$ Laboratory Director, Chemistry department, Birzeit University, Birzeit, Palestine \\ E-mail:hrimmawi@birzeit.edu,mghanem@birzeit.edu, ishalash@birzeit.edu \\ Received November 25, 2009; revised January 7, 2010; accepted February 9, 2010
}

\begin{abstract}
Linear regression and moving averages were used to analyze the patterns of rainfall in eight station in the district of Ramallah and Al-Bireh for the period from 1950's to present. Data analysis showed that a ten years period variability of rainfall but with consistency. It also showed that rainfall in the studied area is not decreasing as mentioned in several previous studies. This area is mountainous and enjoys the Mediterranean climates.
\end{abstract}

Keywords: Linear Regression, Moving Averages, Rainfall Trends, West Bank (Palestine), Mediterranean

\section{Introduction}

The district of Ramallah and Al-Bireh is located within the central mountains of Palestine, (Figure 1). It extends from the district of Nablus in the north to the district of Jerusalem in the south. These mountains are ridges of sloping beds of resistant limestone and dolomite. These ridges include peaks over 800 meters above sea level, and the elevation of the highest peak Tel-Asour, reaches 1016 meters above sea level. The chain of ridges slopes gradually toward the west but slope steeply toward the east. The area generally enjoys a Mediterranean climate of a dry summer and mild, rainy winter. The recorded average of Ramallah's rainfall is about $694 \mathrm{~mm}$ and (minimum rainfall is $307 \mathrm{~mm}$ and maximum rainfall is $1591 \mathrm{~mm}$ ). The standard deviation of rainfall data for the period between 1994 and 2007 is 235 [1]. This is a high standard deviation and refers to rainfall fluctuations from one year to another. The primary cause of rain in Palestine is the moisture transported through the Mediterranean and evaporation from sea surface, followed by orographically-induced condensation over the central Palestinian mountain [2]. In addition, Palestine displays large spatial seasonal and inter annual variability [3].

According to the Palestinian Central Bureau of the Census, in 2007 the district of Ramallah and Al-Bireh were inhabited by 280000 people. In comparison, in the year of 1945 , this district was inhabited by 47280 people [4], and this means that this high growth of the population is putting great stress on the water supply. At present local people believe that the mountains of Ramallah are receiving less rainfall, but the fact of the matter is that Israeli occupation is controlling water resources in the West Bank since 1967 and most of water (80\%) is consumed by Israeli settlers, and the rest is distributed among Palestinian population whose number has jumped dramatically since 1967. For example, in 1967 West Bank population was about 600,000 inhabitants. At present the population has jumped to be 2,350583 [5]. The effects of Israeli pumping of West Bank waters towards settlers are devastating on socio-economic conditions of Palestinian people.

This district was also inhabited by 52834 families and the average family size is 5.3 persons. Water resources in this district vary. For example, there were 44337 (89\%) houses supplied by the public water network, 3621 houses (8\%) supplied by the Israeli network (Mekorot), 817 houses (1.8\%) supplied by wells of gathering rain water, 79 houses $(0.2 \%)$ supplied by springs, 287 houses $(0.6 \%)$ supplied by water tanks, 70 houses $(0.2)$ supplied by other means. The remaining houses $(0.2 \%)$ did not supply information [5]. On the other hand, 262417 people $(93.7 \%)$ in this district were supplied by different kinds of the districts' various water resources; hence the importance of the local annual rainfall to Palestine.

The twin cities of Ramallah and Al-Bireh are not only the center of the district but also have been the central headquarters of Palestinian National Authority since 1994. The district also is close to the Holy city of Jerusalem. In addition, this district is surrounded by rural hinterland, which is composed of 100 villages. 


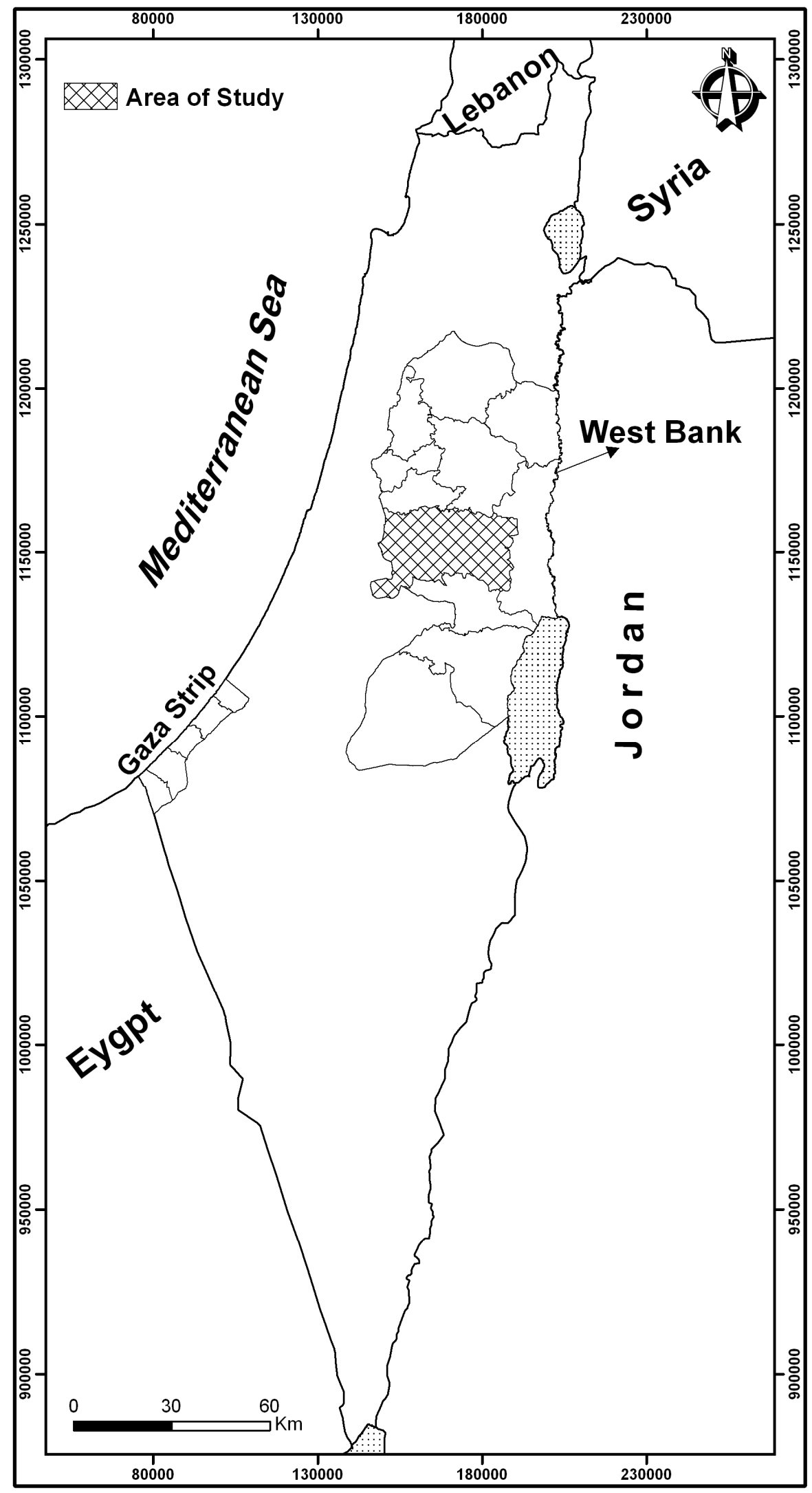

Figure 1. Map of Palestine and area of study. 
Rainfall in Palestine has different uses as a water resources, however, this country is experiencing chronic water shortages. For that climate in general and rainfall trends in specific have received substantial attention by several studies throughout history. For example, outsiders were interested in several aspects of Palestinian climate such as Sperber [6] who reported that Palestine witnessed unusual low rainfall and droughts throughout the period from 2nd to 4th century. Smith [7] reported that Palestine in the 1600's BC was struck by drought due to low rainfall, and the hills were depopulated. Rice [8] studied rainfall in Palestine using recorded rainfall data from 1860 to 1882 . He found that rainfall was highly correlated with possible fertility of the land of Palestine. During droughts inhabitants moved east to better grazing lands in Jordan and vice versa, one reason that many families have links on both sides of the borders. Recently, Sansur [9] determined the cultural heritage ties which connect both societies. Ben-Gai et al. [10], states that changes in temperature of Mediterranean surface since 1960's were responsible for an increase in seasonal rainfall. Price et al. [11] analyzed seasonal rainfall, stream flow, snowfall and lake level data in Israel and found out an indication of enhanced precipitation during winter seasons associated with El Ninos. Steinberger and Gazit-Yaari [12] studied rainfall series in Israel during 1960-1990 for 99 stations and found out that precipitation amounts decreased in the northern, central coastal areas and in northern mountain area. However, precipitation increased in southern coastal area and in western slopes of central mountains. Trends of rainfall were probably the outcome of changes in synoptic climate during winter in the eastern Mediterranean region. In their study about rain spells in Israel, Halfon et al. [13] found a strong correlation between depth of low pressure systems and the rain distribution between the coastal and interior regions. Rainfall patterns were affected by changes in wind speed, the penetration of the humidity inland, and the orographic enhancement efficiency. Rosenfeld [14] and Science Daily [15] reported an inverse relationship between orographic precipitation in the mountains and air pollution coming from Europe. Whether this would be applicable or not in Palestine is needed to be determined since Europe is the source of polluted air masses in winter for the eastern Mediterranean countries. Zangvil, Karas and Sasson [16] found that direct atmospheric agent responsible for the relative increase in seasonal rainfall over the southern part of Israel and decreases in the north. These differences were due to frequency of occurrence of $500 \mathrm{hpa}$ troughs oriented from northeast to southwest, prominent positive cyclonic low pressure anomalies centered over Turkey, and the persistence of a positive phase of the North Atlantic Oscillation. Several studies have pointed out that precipitation may be decreasing in Palestine $[17,18]$.
Pe'er [19] reported that this decrease may have been affected by the decrease in the frequency of mid-latitude cyclones in the eastern Mediterranean. On the other hand, Goldreich [20] reported an increase in amounts of annual rainfall in Israel by about 3\%.

On a regional level, several studies were carried looking at precipitation changes. For example, Dahamsheh and Aksoy [21] carried out a study about structural characteristics of annual precipitation in thirteen meteorological stations distributed across Jordan covering the period from 1953 to 2002 . They concluded that precipitation in Jordan was consistent in time, however randomness was evident. Tarawneh and Kadioglu [22] described the climate regions in Jordan and they have explained more than $90 \%$ of its precipitation variation. Ghanem [23] by employing simple moving averages and least square regression, tackled and analyzed rainfall trends in Jordan using recorded data since the 1930's for several weather stations. Smadi and Zghoul [24] examined the recent changes, trends and fluctuations of rainfall and number of rain days at the Amman Airport Meteorological, Madaba, and Mafraq stations during 19222003. Their study showed an abrupt change in 1957 in the total rainfall and annual number of rain days. In addition, a decline in total rainfall and rainy days during the second half of 20th century were observed. Alvi [25] reported that Middle Eastern countries are suffering from desertification or degradation as a result of climatic changes. Pita, Camarillo and Aguilar [26] used the technique of moving averages of 30 -year period to find the variability over time in Andalusia and its links with the North Atlantic Oscillation. The study has concluded that variability of rainfall in Andalusia alternates between being extreme or low separated by periods of transition. Luterbacher and Xoplaki [27] studied 500-year winter temperature and precipitation (1500-2000) variability over the Mediterranean area and its connection to the large-scale atmospheric circulation. The time series showed an unprecedented trend towards winter dryness over the last decades of the twentieth century. Periods of dry/wet and warm/cold periods were influenced by changes in the atmospheric circulation. Felis et al. [28] found out that cold periods in the Middle East since 1750 "were more accompanied by more arid conditions in the northern Red Sea but increased precipitation in the southeastern Mediterranean region, whereas warm periods were accompanied by decreased rainfall in the latter and less arid conditions in the northern Red Sea". Paliatsos et al. [29] studied the spatial distribution of precipitation trends in Greece and found a significant decreasing precipitation trend during the cold season in which $80 \%$ of the annual precipitation amounts typically occur. Pnevmatikos and Katsoulis [30] studied the changing rainfall regime in Greece and its impact on climatologically means and precipitation found that rainfall amounts 
began to decline in 1980 's, a trend which has continued to recent years. Alpert et al. [31] found out an increase of Mediterranean extreme daily rainfall in spite of decreases in total values in Italy and Spain, but not in Cyprus and Palestine. Subyani and Al-Dakheel [32] used multivariate geostatistics for regional analysis and prediction of rainfall throughout the southwest region of Saudi Arabia. They found out that regional mean annual rainfall could not be predicted by the influence of elevations because the studied area was influenced by several climatological conditions.

On global level, Alexander et al. [33] stated that world temperature and rainfall were increasing. Moving averages were also used by Kwanyuen [34] in analyzing rainfall changes in north of Thailand. Long term changes in rainfall and potential wheat yields at Brisbane, Australia were analyzed by using 10 -year moving averages by Robinson and Freebairm [35]. Twelve months moving averages of rainfall in West Hawaii from 1985 to present was employed by USGS Pacific Islands Water Science Center [36]. Naido et al. [37] used moving averages and linear regression techniques to analyze rainfall trends in India. They found that rainfall indicates a triennial cycle and significant periods in the range from 3 to 8 years. Hills [38] used moving averages to find out the causes of recent droughts in Fly Gap Division of the Double Helix Ranch, Texas. Hills related the drought in the area by the occurrences of El Nino. When the western Pacific Ocean temperatures rise, rainfall increases and vice versa when temperatures of the same ocean fall rainfall decreases. In Costa Rica, Longino [39] used moving averages to find out trends that connect seasonal rainfall and shoot production. The study concluded that shoot production was high during dry season (from January to early April) and low production during wet season (April to December). Markham [40] used moving averages to find out the periodicities in rainfall at Fortaleza, Ceara, Brazil. He found out that this area of study gets either much rain or dryness and were sensitive to wind shifts to the north or south. Leedman [41] used moving averages to show the extent and historical frequency of a rainfall deficiency in Australia. Least square regression was used by Wiwantikit [42] to find the correlation between dengue infection and rainfall in central region of Thailand in 2004.

The aim of this paper is to analyze the rainfall trends in several spots of the district of Ramallah and Al-Bireh, West Bank Palestine, from 1950's to present. This research is also aimed to find out whether the district of Ramallah and Al-Bireh has more or less rainfall that would be expected to occur. Furthermore, the study is a part of project concerned with disseminating the importance of rainfall recording in Palestinian schools and municipalities.

By using moving averages and linear regression analysis it has been demonstrated that an approximately ten-year period variability of rainfall in Ramallah and
Al-Bireh district of Palestine. Rainfall in this district is not decreasing but it is similar to that of the West Bank which is mountainous and enjoys the Mediterranean climate.

Since patterns of rainfall variability have rarely been mentioned in literature of Arab countries, this study is of particular interest to policy makers of countries of the Eastern side of the Mediterranean in general and to Palestine in specific in regards to the effects of rainfall trends upon water resources, human needs, agriculture, and industry.

\section{Methods of Study}

Recorded rainfall data was collected from offices of Palestinian National Authority, and the research team which includes three faculty members collected recorded rainfall data from eight schools in which some have been recording annual rainfall data since 1950's and other schools since 1960's. Five year period trends, moving averages, and linear regression were used to determine rainfall trends and periodical alternations.

For the purpose of recording rainfall data for the year of 2007-2008 and the coming years, the research team has distributed 38 manual rain gauges to 38 randomly selected schools in the district. The team visited the 38 schools and trained geography and science teachers of ways to record rainfall. Contacts took place between the research team and the selected schools. Schools administrations and teachers became aware of the importance of rainfall recording and will keep carrying out this recording for the next coming years. Throughout the academic year the team managed to collect the recorded rainfall data from several schools. The recorded data were analyzed using moving averages and least square regression.

\section{Results and Discussions}

Moving averages and linear regression analysis were employed for the purpose of analyzing the recorded rainfall data at eight schools which are located within the area of study. These schools managed to keep rainfall records since 1950's or 1960's until present. However, some of them missed some records because of the political instability and the alterations of schools administrations and governments such as Jordan, Israel and Palestine National Authority. Rainfall for five-year moving averages and least square regression line indicate that rainfall in eight schools did not show decline. However, the charts of moving averages for five years showed that the studied area receives rainfall in a type of alternation period. Data of eight schools may be divided into three categories. First, the regression line of Dir Dibwan showed an increasing trend of their rainfall (Figure 2). 

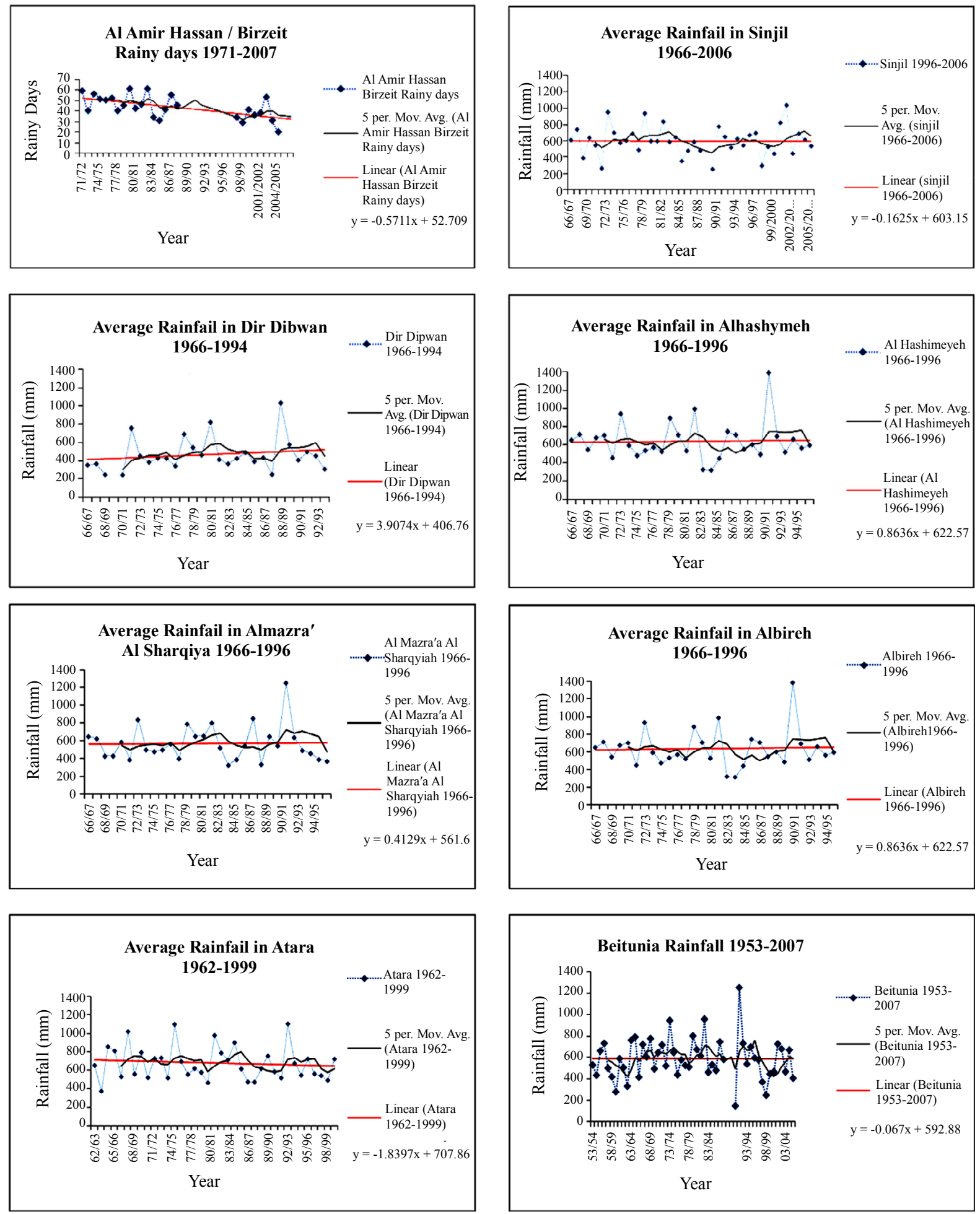

Figure 2. Average rainfall and 5 year moving averages in Ramallah and Al-Bireh District.

This station received more rainfall because it is the highest and located on top of Ramallah Mountains. Second, the regression line of Atara and Al-Amir Hasan (Birzeit) secondary schools showed an obvious decline in their re- corded rainfall data. It is possible this may be explained by the unavailability of a complete record. Third, no trend is evident for five high school stations, Al-Bireh, Al-Hashimeyeah, Beituunia, Al-Mazra'a Al-Shraqiyah and Sinjil. 
Five-year moving averages and the least-square regression line for average rainfall of eight stations from 1953 until 2005 (Figure 3) also illustrates that rainfall has been mostly steady, but with some alternation about the regression line.

Average rainfall values and regression lines for 49 rainfall stations in the West Bank from 1968 to 1997 (Figure 3) are similar to the results of the studied 8 stations in the district of Ramallah. Furthermore, fluctuation periods of five-years moving averages are also similar. This is reasonable, given that the central Mountains of the West Bank are similar in terms of their climatological conditions.

Initiating daily and annual rainfall recording at schools a significant factor in spreading the values of rainfall recording. It has been observed that schools which kept recording rainfall data consider it as a part of their school educational system and cultural heritage. The collected data from eight schools were significant factors in helping to spread the word of importance of rainfall and water among teachers, students and their local communities.

\section{Conclusions}

Using moving averages and linear regression analysis we have demonstrated an approximately ten-year period
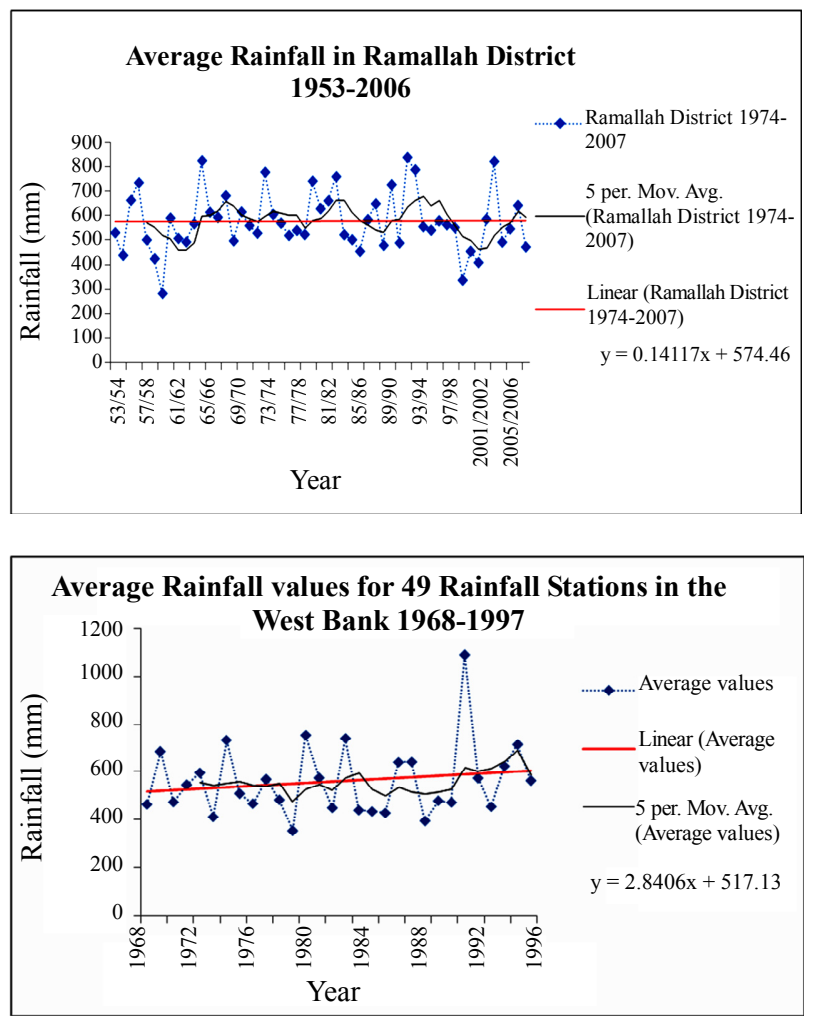

Figure 3. Average rainfall and 5 year moving averages in Ramallah and Al-Bireh District and the West Bank. variability of rainfall in the Ramallah And Al-Bireh district of Palestine. For most stations, rainfall has not decreased as has been stated by Smadi and Zghoul[24], Pnevmatikos and Katsoulis [30], Paz et al. [17], Ben-Gai et al. [10] and Steinberger and Gazit-Yari [12]. In addition, pattern of rainfall in this district is also similar to that of the West Bank rainfall. In fact West Bank mainly composed of mountains which are similar in terms of their Mediterranean climatological conditions. However, findings of this study agree with Dahamsheh and Aksoy [21] who found that rainfall in Jordan was consistent over the period from 1953 to 2002. Furthermore, rainfall variability in the district of Ramallah also agrees with Tarawneh and Kadioglu [22] who states that precipitation in Jordan varies from one period to another, and with the study of Pita, Camarillo and Aguilar [26] who carried a study over Andalusia.

It is recommended to carry out studies of other areas in Palestine and neighboring countries in order to find out similarities and differences in rainfall patterns. Since water consumption for different purposes is increasing as a result of population increase people should be aware of water significance. In addition, violation of International laws by Israel as an occupying power of the Palestinian lands should be addressed at the United Nations levels. Palestinians should have complete control of their water resources.

\section{References}

[1] District of Jerusalem, "Rainfall Distribution Plan, Ramallah, and Al-Bireh, 1974-2007," Authority of Water in the district of Jerusalem, Un Published data sheet, 2007.

[2] A. Isakson, "Rainfall Patterns over Central and Southern Israel Induced by Large-Scale Moisture Flux," Journal of Applied Meteorology, Vol. 35, 1996, pp. 1063-1075.

[3] J. P. Evans, R. B. Smith and R. Oglesby, "Middle East Climate Simulation and Dominant Precipitation Processes," International Journal of Climatology, Vol. 24, 2004, pp. 1671-1694.

[4] Kunoooze and Dafain, "The City of Ramallah," 2009. http://kunooze.com/vb374/showthread.php?t=4175.

[5] Palestinian Central Bureau of Statistics, "Population in the West Bank by Governate and Sex," 2009. http://www. pcbs.gov.ps/Portals/_PCBS/Downloads/book1487.pdf

[6] D. Sperber, "Drought, Famine and Pestilence in Amoraic Palestine," Journal of the Economic and Social History of the Orient," Vol. 17, No. 3, September 1974, pp. 272-298.

[7] A. Smith, "Hyksos and the Exodus," 2008. https:/listhost.uchicago.edu/pipermail/ane/2003-October/010855.ht $\mathrm{ml}$

[8] E. W. Rice, "Rainfall in Palestine," Journal of the Society of Biblical Literature and Exegesis, Vol. 6, No. 1, 1886, pp. 69-72.

[9] R. Sansur, "Natural Heritage in Palestine," 2006. http:// 
www.palestine-family.net/index.php?nav $=6-26 \& \operatorname{cid}=13 \&$ $\operatorname{did}=2267 \&$ pageflip=1

[10] T. Ben-Gai, A. Manes and P. Apert, "Long-Term Changes in Annual Rainfall Patterns in Southern Israel," Theoretical and Applied Climatology, Vol. 61, 1994, pp. 177-190.

[11] C. Price, L. Stone, A. Huppert, B. Rajagopalan and P. Alpert, "A Possible Link between El Nino and Precipitation in Israel," Geophysical Research Letters, Vol. 25, No. 21, November 1998, pp. 3963-3966.

[12] E. H. Steinberger and N. Gazit-Yaari, "Recent Changes in the Spatial Distribution of Annual Precipitation in Israel," Journal of Climate, Vol. 9, No. 12, 1996, pp. 33283336, 1996.

[13] N. Halfon, H. Kutiel and B. Ziv, "The Rain Spells in Israel-Major Spatial Patterns and their Synoptic Conditions," 8th Plinius Conference on Mediterranean Storms and Extreme Events in an Era of Climate Change, Dead Sea, 17-20 October 2006.

[14] D. Rosenfeld, et al., "Inverse Relations between Amounts of Air Pollution and Orographic Precipitation," Science, Vol. 315, No. 5817, March 2007, pp. 1396-1398.

[15] Science Daily, "Pollution Reduces Rainfall in Hilly Areas," 2008, pp. 1-3. http://www.sciencedaily.com/releases /2007/03/070308220825.htm.

[16] A. Zangvil, S. Karas and A. Sasson, "Connection Between Mediterranean Seasonal Mean 500 hpa Height and Sea-Level Pressure Patterns and the Spatial Rainfall Distribution," International Journal of Climatology, Vol. 23, No. 13, 2003, pp. 1567- 1576.

[17] S. Paz, H. Kutiel and H. Steinberger, "Recent Changes in Precipitation Patterns along the Coast of the Eastern Mediterranean," 2nd European Conference on Applied Climatology, Vienna, 19-23 October, 1998.

[18] B. A. Ben-Gai, A. Manes and S. Rubin, "Spatial and Temporal Changes in Rainfall Frequency Patterns in Israel," Theoretical and Applied Climatology, Vol. 49, No. 2, June 1998, pp. 56-67.

[19] G. Pe'er, "Climate Change: Israel National Report under the United Nations Framework Convention on Climate Change: Impact, Vulnerability and Adaptation," 2000. http://nasa.proj.ac.il/Israel-Research/Climate_Change_Isr ael_National_Report.html

[20] Y. Goldreich, "Temporal Variations of Rainfall in Israel," Climate Research, Vol. 5, 1995, pp. 179-195.

[21] A. Dahamsheh and H. Aksoy, "Structural Characteristics of Annual Precpitation Data in Jordan," Theoretical and Applied Climatology, Vol. 88, 2007, pp. 201-212.

[22] Q. Tarawneh and M. Kadioglu, "An Analysis of Precipitation Climatology in Jordan," Theoretical Applied Climatology, Vol. 74, No. 1-2, 2002, pp. 123-136.

[23] A. Ghanem, "Analysis of Possible Rainfall in Arid and Semi Arid Areas in Jordan," Journal of Damascus University, Vol. 17, No. 2, 2001, pp. 13-27.

[24] M. M. Smadi and A. Zghoul, "A Sudden Change in Rainfall Characteristics in Amman, Jordan during the Mid 1950's," American Journal of Environmental Sciences,
Vol. 2, No. 3, 2006, pp. 84-91.

[25] S. Haque Alvi, "Climatic Changes and Desertification in Some Regions of the Middle East," GeoJournal, Vol. 37, No. 4, December 2004, pp. 483-488.

[26] M. F. Pita, J. M. Camarillo and M. Aguilar, "Rainfall Variability Pattern over Time in Andalousia and its Links with the North Atlantic Oscillation," In: C. Lisboa, Ed., Climate and Environmental Change, 1998, pp. 77-89.

[27] J. Luterbacher and E. Xoplaki, "500-Year Winter Temperature and Precipitation Variability over the Mediterranean Area and its Connection to the Lareg-Scale Atmospheric Circulation," In: H.-J. Bolle, Ed., Mediterranean Climate, Variability and Trends, Springer-Verlag, Heidelberg, 2003, pp. 133-153. http://ao.atoms.colostate. edu/other-papers/Documents5.pdf.

[28] T. Felis, J. Patzold, Y. Loya, M. Fine and A. Nawar, "A Coral Oxygen Isotope Record from the Northern Red Sea Documenting NAO, ENSO, and North Pacific Teleconnections on Middle East Climate Variability since the Year 1750," Paleoceanography, Vol. 15, No. 6, 2000, pp. 679-684.

[29] A. G. Paliatsos, H. D. Kambezidis, P. T. Nastos, M. D. Kariofilli and E. G. Kastrada, "The Spatial Distribution of Precipitation Trends in Greece," 7th Panhellenic Geographical Conference of the Hellenic Geographical Society, Mytilene, 14-17 November 2004.

[30] J. D. Pnevmatikos and B. D. Katsoulis, "The Changing Regime in Greece and its Impact on Climatological Means," Meteorological Applications, Vol. 13, 2006, pp. 331345.

[31] P. Alpert, "The Paradoxical Increase of Mediterranean Extreme Daily Rainfall in Spite of Decreases in Total Values," Geophysical Research Letters, Vol. 29, No. 22, 2002, pp. 1013-1021.

[32] A. M. Subyani and A. M. Al-Dakheel, "Multivariate Geostatistical Methods of Mean Annual and Seasonal Rainfall in Southwest Saudi Arabia," Arab Journal of Geosciences, Vol. 2, 2009, pp. 19-27.

[33] L. W. Alexander, et al, "Global Change in Daily Climate Extremes of Temperature and Precipitation," 2008. http:// secamlocal.ex.ac.uk/people/staff/dbs202/publication /2005/alexander.pdf.

[34] B. Kwanyuen, "Comparative Study of Rainfall in the North of Thailand. Department of Irrigation Engineering," Faculty of Engineering, Kasetsart University, Thailand, 2008, pp. 1-9. http://std.cpc.ku.ac.th/delta/conf/ Acrobat/Papers_Eng/Volume\%201/Banchaa.pdf.

[35] A. Robinson and D. Freebarim, "Long-term Changes in Rainfall and Potential Wheat Yields at St. George," Department of Natural Resources, Toowoomba, 2008. http://www.google.com/search?hl=en\&q=Long-term + Ch anges + in + Rainfall + and + Potential + Wheat + Yiel-ds + at + St. + George\&btnG $=$ Search.

[36] USGS Pacific Islands Water Science Center, "Recent Hydrologic Conditions," West Hawaii, 2008, pp. 1-27. http://hi.water.usgs.gov/west_hawaii_tab.htm.

[37] C. V. Naidu, B. R. Srinivasa Rao and D. V. Bhaskar Rao, 
"Climate Trends and Periodicities of Annual Rainfall Over India," Meteorological Applications, Vol. 6, No. 4, December 1999, pp. 395-404.

[38] D. M. Hillis, "Rainfall Patterns at the Fly Gap Division of the Double Helix Ranch, Mason County, Texas," University of Texas, 2008. http://doublehelixranch.com/FlyGap RainTrends/html.

[39] J. T. Longino, "A Negative Correlation between Growth and Tainfall in a Tropical Liana: Cost Rica," Biotropica, Vol. 18, No. 3, September 1986, pp. 195-200, 1986.

[40] B. G. Markham, "Apparent Periodicities in Rainfall at
Fortaleza, Ceara, Brazil," Journal of Applied Meteorology, Vol. 13, 1973, pp. 176-179.

[41] A. Leedman, "BRS Use of Climatic Information to Analyse Drought Events," Bureau of Rural Sciences, 2003, pp. 1-4. http://www.bom.gov.au/climate/droughtcom/abstracts/ Leedman.pdf

[42] V. Wiwantikit, "Strong Correlation between Rainfall and the Prevalence of Dengue in Central Region of Thailand in 2004," Journal of Rural and Tropical Health, Vol. 4, 2005, pp. 41-42. 